\title{
Gross Motor Skills of Hong Kong Preschool Children 本港幼兒學童的粗略運動技能
}

\author{
Bik Chu CHOW \\ Department of Physical Education, \\ Hong Kong Baptist University, HONG KONG \\ 周碧珠 \\ 香港浸會大學體育學系
}

\author{
Lily CHAN \\ Department of Educational Psychology, \\ The Chinese University of Hong Kong, HONG KONG \\ 陳莉莉 \\ 香港中文大學教育心理學系
}

\begin{abstract}
The purpose of this study was to determine the gender difference in gross motor performance of Hong Kong preschool children. The secondary purposes were to determine whether there was a relationship between body mass index and motor performance as well as to determine the influence of preschool types (large play area vs. small play area) on the motor performance of preschool children. A total of 239 children (121 boys, 118 girls) aged 3 to 6 years from two types of preschools was assessed on locomotor and object control skills of the Test of Gross Motor Development (TGMD-2, Ulrich, 2000). Results showed that there was no gender difference in children's gross motor skills when adjusted by the age effect. There was also no relationship between body mass index and motor performance of preschool children. When partial out age effect, children from preschools with larger play area performed better locomotor skills than those from preschools with smaller play area, however, children from preschools with larger play area had worse object control skills than those from preschools with smaller play area.
\end{abstract}

\section{摘 要}

本研究目的是調查幼兒學童之肌動技能表現, 此研究樣本包括二百三十九名年齡介乎三至六歲來自四間幼稚園的香港學童(男 童=121, 女童=118) , 測試項目共有六項身體移動、六項物件操控及身高、體重。結果顯示研究分析若分離年齡的影響, 幼兒之 肌動技能表現是沒有性別差異。而體質指數亦與幼兒之肌動技能表現沒有顯著相關。另外, 學童就讀於較大活動埸地的幼兒園於 身體移動技能上，較那些就讀較小活動埸地的幼兒園為佳，反之，前者於物件操控技能上較後者為差。

\section{Introduction}

Motor development is a lifelong process. Gallahue and Ozmun (2006) depicted a transactional view of causes and interactions among individual factors (e.g., heredity), environment factors (e.g., experience, learning), and task factors (e.g., physical and mechanical factors) in which motor development can be studied as a process. On the other hand, motor development can be studied as a product in which movements produced can be described by words or compared with normative data in various human stages (infancy, childhood, adolescence, and adulthood).
One classification of movements is the distinction of gross versus fine motor skills. This paper focuses solely on the development of gross motor skills. In order to achieve specialized sport skill proficiency, a person goes through different stages of motor development. Gallahue and Ozmun (2006) presented this model on the phases of motor development with different movement phases in corresponding to the human age. The first phase of the model is the reflexive movement phase that starts at birth to one year old which is followed by the second phase of rudimentary movement phase of stability movements such as gaining control of the head, neck, and trunk 
muscles; and other movements like finger grasping and the locomotor movements of creeping, crawling, and walking. The rudimentary movement phase starts at one to two years old. The third phase is the fundamental movement phase that starts at two to seven years and the last phase is the specialized movement phase that starts at seven to fourteen years and up.

Development of fundamental movement skills of the third phase of motor development (Gallahue \& Ozmun, 2006) is basic to the development of motor abilities of children. The fundamental movement phase represents a time young children actively explore with the movement. The toddler learns to walk, run, jump and perform manipulative skills such as throwing and catching a ball. A child begins to learn fundamental movement skills which are composed of locomotor skills and object control skills. Locomotor skills involve moving the body through space and include skills such as running, jumping, skipping, hopping, sliding (Haywood \& Getchell, 2009). Object control skills involve manipulation and projection objects such as throwing, catching, dribbling, kicking and striking balls (Haywood \& Getchell, 2009). These skills form the foundation for future learning of sport specific skills (Clark \& Metcalfe, 2002). As stated by Payne and Issacs (2008), preschool children are involved in the process of developing and refining fundamental movement abilities. Although preschool children in their early growing years can perform more complex movement as they increase in age due to growth and maturity, continuous practice and instruction are required to reach for mature stage in motor development.

In motor performance studies, gender difference is often a key research area. However, conflicting results were shown. In an earlier study, Eaton and Enns (1986) found that gender difference in motor performance increases through the preschool years. However, others found no gender difference in motor abilities in preschool aged children (Elisanna, Konstantina \& Vasilios, 2005; Pennington \& Kelly, 2002).

When studying motor performance of children, apart from age and gender, other variables have been found to be correlated with motor performance of children. They range from internal factors such as the child's temperament, to the external factors such as the home environment. This present paper highlights on one factor: preschool type. The influence of preschool type setting (public vs. private) has been studied (Giagazoglou, Karagianni, Sidiropoulou, \& Salonikidis, 2008). Their results revealed that children who attended the private preschool type setting with plenty open space for free play had higher gross motor abilities than children who attended the public preschool centers with limited spaces for free play.

Studies of motor performance have employed different observation scales, among the commonly used ones is the Test of Gross Motor Development (TGMD) measure. The first edition of Test of Gross Motor Development (TGMD) was developed by Ulrich in 1985. The second edition of Test of Gross Motor evelopment (TGMD-2) was developed in 2000. The TGMD-2 is a process-oriented gross motor skills assessment and provides users with criterionreferenced and norm-referenced interpretations.

In recent years, researchers have studied motor skills of preschool children (e.g., Haga, Pedersen \& Sigmundsson, 2008; Livonen, Saakalahti, \& Nissinene, 2011; Roth et al., 2010; Shala, 2009; Wang, 2004). In the local context, Wong (2006) assessed the scale characteristics of TGMD-2 on the motor performance of a cross-sectional sample of 1228 Hong Kong children aged 3 to 10. Another two local studies that used TGMD-2 for motor performance assessment were conducted on Hong Kong elementary children aged 6-8 or 6-9 (Choi Tse, 2004; Pang \& Fong, 2009). However, there is a lack of studies determining the influence of types of preschools on the motor skills of Hong Kong preschool children. The purpose of the present study was first to determine the gender difference in gross motor performance of Hong Kong preschoolers aged 3 to 6 years. The secondary purposes were to determine the relationship between body mass index and motor performance as well as the influence of types of preschools on the gross motor skills of preschool children.

\section{Methods}

Two hundred and thirty-nine children aged 3 to 6 years from 4 preschools in Hong Kong participated in the study. The selection of the preschools was based on two criteria: different play area size and similar class size. Two of the four preschools have larger play area that is at least twice of the size of the traditional preschools' play area. The other two preschools have traditional play area size (e.g., $100 \mathrm{~m}^{2}$ total play area). These four 
preschools have similar class size of around 20-25. Around 60 children from each preschool were randomly selected by grade level and by gender. Therefore, around 10 boys and 10 girls from each grade level (three levels: $\mathrm{K} 1, \mathrm{~K} 2, \mathrm{~K} 3$ ) in a preschool were tested on motor skills measures and body height and body weight measures. Permission for conducting the study was obtained from the preschool principals and informed consent forms were signed by the parents of the study participants.

\section{Motor Skills Measures}

The Test of Gross Motor Development-Second Edition (TGMD-2, Ulrich, 2000) was adopted to measure the motor skill abilities of the children. It contains a total of 12 motor tests categorized into 2 subtests, the locomotor (run, gallop, hop, leap, horizontal jump, slide) and object control (striking a stationary ball, stationary dribble, catch, kick, overhand throw, underhand roll). Furthermore, each skill contains 6 to 10 components for scoring by either 1 or 0 being given to show the presence or absence of that particular skill component. Therefore, raw score for each skill is computed by adding up all component scores. Then, raw scores can be added up across skills to form a subset of locomotor score or object control score, which range from 0 to 48 points. For this study, the procedures for data collection of testing TGMD-2 followed the test manual (Ulrich, 2000). On the other hand, TGMD-2 was shown to have high reliability with reliability coefficients for total score, locomotor and object control subtests being 0.91, 0.85, and 0.88, respectively (Ulrich, 2000). Based on confirmatory factor analysis of large sample of Hong Kong children aged 3 to 10 , Wong (2004) supported the two-factor solution of TGMD-2 and found it to be reliable.

\section{Testing Procedures}

The TGMD-2 was conducted in this sequence: run, gallop, hop, leap, horizontal jump, slide, striking a stationary ball, stationary dribble, catch, kick, overhand throw and underhand roll. Children queued behind a red line and performed a skill test in an area within 50 feet of clear space. During each test, the test examiner gave verbal description of the skill and demonstration. Then, a practice trial was provided for the child who queued at the front. An additional practice trial was given if the child did not seem to understand the task. For each motor skill test item, the child was given two test trials. After completion of a test, children then queued in different order so that no one child would always go first or last. Other measuring variables were the children's body height and weight. Body mass index was computed from height and weight data.

All children's motor performance was assessed by a test examiner from the video tapes. The test examiner had prior training in using TGMD-2. She was trained again by video-tapes together with the scoring exercises for 6 hours. In order to provide data accuracy, a digital video camera was set up during all motor skill measures. This allowed the examiner to review and evaluate the children's motor performance based on video-tapes.

\section{Treatment of Data}

Data were analyzed with the Statistical Package for the Social Sciences (PASW Statistics 18). Variables analyzed included the raw scores of the locomotor skills and object control skills, the total raw scores of the TGMD-2, and the body mass index. Categorical variables were gender, age, and type of preschools. All statistical tests were performed with the alpha level of 0.05 .

\section{Results}

Two hundred and thirty-nine (121 boys, 118 girls) preschool children aged 3 to 6 years with mean age of $3.6(\mathrm{SD}=0.2)$ were assessed on motor performance. Table 1 contains the descriptive statistics of motor ability by age and by gender. Results showed an increasing trend of motor ability with the increasing age of the children.

When determining the gender difference of motor ability of preschool children, results showed that there was no gender difference in locomotor $(\mathrm{F}=3.92, \mathrm{p}=0.05)$, object control skills $(\mathrm{F}=0.80, \mathrm{p}=0.37)$ and total score of TGMD-2 ( $\mathrm{F}=2.86, \mathrm{p}=0.09)$ after adjusted for children's age. However, if age was not adjusted, gender differences were found for all motor skill measures with boys having better motor performance scores than girls. By computing partial correlation between preschool children's body mass index (BMI) and motor performance scores, there was no correlation between BMI and any one of the motor performance scores (locomotor, object control, total) with correlation coefficients of $0.01,0.43,0.03$, respectively. 
Using 2X2 ANCOVA with age as covariate and independent variables of preschool types (small play area vs. large play area) and gender, there were no significant interaction effects and there were no significant gender main effects in locomotor, object control, and total scores of TGMD. However, there was significant main effect of school types in locomotor and object control scores but there was no significant main effect of school types in total score of TGMD. Children of preschools with larger play area performed significantly $(\underline{\mathrm{F}}=14.34, \mathrm{p}=0.00$; partial $\eta^{2}=0.06$ ) better in locomotor skills than children of preschools of smaller paly area (mean locomotor scores: $30.61 \pm 0.61$ vs. $27.35 \pm 0.61$ ). However, a reverse trend was observed for object control in which children of preschools with smaller play area exceled in object control skills $\left(\underline{\mathrm{F}}=5.35, \underline{\mathrm{p}}=0.02\right.$; partial $\left.\eta^{2}=0.02\right)$ than those children of preschools of larger play area (mean object control scores: $25.82 \pm 0.65$ vs. $23.70 \pm 0.65$ ).
When comparing percentile scores of motor performance of preschool children in the present study with Wong's (2004) study of a much larger sample size, results showed that children in the present study seemed to score higher in object control skills in both boys and girls than the sample in Wong's study (see Table 2). In general, children in the present study had similar scores in locomotor skills as in Wong's sample across different ages. As a result of the higher scores in object control skills of the present sample, there was an increasing trend of total scores of the TGMD-2 of the present sample when comparing with the total scores of the TGMD-2 of the sample in Wong's study.

Table 1. Descriptive Statistics of Motor Skills and Anthropometric Measures of Hong Kong Preschool Children (N=239).

\begin{tabular}{lllllll}
\hline & Age & $\mathrm{N}$ & $\mathrm{M}$ & $\mathrm{SD}$ & Min & Max \\
\hline Locomotor & $3-3.9$ & 53 & 22.34 & 7.60 & 8 & 36 \\
& $4-4.9$ & 68 & 25.65 & 6.63 & 10 & 40 \\
& $5-5.9$ & 80 & 34.03 & 6.75 & 18 & 48 \\
Object Control & 6 & 38 & 33.61 & 6.17 & 16 & 45 \\
& $3-3.9$ & 53 & 18.83 & 6.51 & 6 & 32 \\
& $4-4.9$ & 68 & 22.38 & 5.95 & 10 & 37 \\
Total Score & $5-5.9$ & 80 & 28.86 & 8.60 & 11 & 46 \\
& 6 & 38 & 28.79 & 7.56 & 13 & 46 \\
& $3-3.9$ & 53 & 41.17 & 11.73 & 22 & 66 \\
Body Height & $4-4.9$ & 68 & 48.03 & 10.53 & 25 & 73 \\
(kg) & $5-5.9$ & 80 & 62.89 & 13.56 & 32 & 92 \\
& 6 & 38 & 62.39 & 10.89 & 41 & 85 \\
Body Weight & $3-3.9$ & 53 & 99.28 & 3.86 & 92.5 & 107.0 \\
$(\mathrm{~cm})$ & $4-4.9$ & 68 & 105.05 & 4.62 & 96.1 & 114.3 \\
& $5-5.9$ & 80 & 111.39 & 4.45 & 100.1 & 120.6 \\
& 6 & 38 & 115.69 & 4.55 & 105.3 & 126.2 \\
Body Mass & $3-3.9$ & 53 & 35.33 & 4.41 & 27.9 & 45.0 \\
Index (BMI, & $5-4.9$ & 68 & 38.72 & 7.08 & 31.0 & 79.2 \\
Kg/Ht $\left.{ }^{2}\right)$ & $6-9.9$ & 80 & 43.62 & 6.32 & 32.9 & 59.8 \\
& $4-4.9$ & 38 & 46.27 & 5.12 & 36.2 & 56.8 \\
\hline
\end{tabular}


Table 2. Percentiles of Locomotor, Object Control and Total Scores of the TGMD-2 of Children by Age and by Gender ( $\mathrm{N}=239)$ as Compared with Local Norm.*

\begin{tabular}{|c|c|c|c|c|c|c|c|c|}
\hline & \multicolumn{8}{|c|}{ Age } \\
\hline & \multicolumn{3}{|c|}{ Boys } & & & \multicolumn{3}{|c|}{ Girls } \\
\hline Percentile & $3-3.9$ & $4-4.9$ & $5-5.9$ & $6-6.9$ & $3-3.9$ & $4-4.9$ & $5-5.9$ & $6-6.9$ \\
\hline$n$ & 22 & 29 & 44 & 26 & 31 & 39 & 36 & 12 \\
\hline \multicolumn{9}{|l|}{ Locomotor } \\
\hline $10^{\text {th }}$ & $13(10)$ & $18(16)$ & $25(25)$ & $29(29)$ & $13(15)$ & $16(15)$ & $26(26)$ & $18(26)$ \\
\hline $25^{\text {th }}$ & $17(16)$ & $20(21)$ & $28(29)$ & $31(33)$ & $16(20)$ & $20(23)$ & $29(31)$ & $27(33)$ \\
\hline $50^{\text {th }}$ & $24(22)$ & $27(31)$ & $35(34)$ & $33(37)$ & $20(24)$ & $24(28)$ & $34(35)$ & $33(39)$ \\
\hline $75^{\text {th }}$ & $32(26)$ & $31(37)$ & $41(38)$ & $38(40)$ & $25(28)$ & $31(33)$ & $37(38)$ & $40(41)$ \\
\hline $90^{\text {th }}$ & $35(29)$ & $33(40)$ & $45(43)$ & $42(43)$ & $32(31)$ & $35(42)$ & $41(42)$ & $44(44)$ \\
\hline \multirow{2}{*}{\multicolumn{9}{|c|}{$\begin{array}{l}\text { Object } \\
\text { Control }\end{array}$}} \\
\hline & & & & & & & & \\
\hline $10^{\text {th }}$ & $13(2)$ & $16(10)$ & $17(13)$ & $17(18)$ & $9(3)$ & $13(8)$ & $17(11)$ & $17(15)$ \\
\hline $25^{\text {th }}$ & $15(9)$ & $19(13)$ & $23(17)$ & $21(23)$ & $14(7)$ & $17(11)$ & $21(15)$ & $30(18)$ \\
\hline $50^{\text {th }}$ & $20(13)$ & $22(17)$ & $30(22)$ & $28(27)$ & $17(12)$ & $22(15)$ & $28(18)$ & $34(23)$ \\
\hline $75^{\text {th }}$ & $28(18)$ & $27(22)$ & $38(28)$ & $32(32)$ & $20(17)$ & $25(18)$ & $34(21)$ & $37(27)$ \\
\hline $90^{\text {th }}$ & $31(22)$ & $31(25)$ & $42(33)$ & $38(37)$ & $24(20)$ & $32(21)$ & $41(25)$ & $38(32)$ \\
\hline \multicolumn{9}{|l|}{ Total } \\
\hline $10^{\text {th }}$ & $28(21)$ & $36(31)$ & $45(41)$ & $47(51)$ & $25(23)$ & $32(28)$ & $48(41)$ & $45(44)$ \\
\hline $25^{\text {th }}$ & $35(26)$ & $41(37)$ & $52(49)$ & $54(57)$ & $32(29)$ & $40(34)$ & $52(48)$ & $53(51)$ \\
\hline $50^{\text {th }}$ & $48(34)$ & 49 (47) & $62(57)$ & $61(63)$ & $36(37)$ & $47(42)$ & $61(52)$ & $67(62)$ \\
\hline $75^{\text {th }}$ & $60(41)$ & $57(56)$ & 77 (64) & $68(70)$ & $42(43)$ & $53(50)$ & $72(58)$ & $74(68)$ \\
\hline $90^{\text {th }}$ & $64(49)$ & $62(61)$ & $86(70)$ & $78(75)$ & $53(48)$ & $65(56)$ & $75(63)$ & $79(70)$ \\
\hline
\end{tabular}

*Scores in bracket are referenced from Wong (2004) study with 652 Hong Kong preschool children aged 3-6 years.

\section{Discussions}

Development of fundamental movement skills is particularly important for preschool children because it can determine whether the children have sufficient proficiency to progress up to more sport specialized movement phase (Gallahue \& Ozmun, 2006). One of the purposes of this study was to determine the gender difference of motor performance of preschool children aged 3 to 6 . By examining the raw data of the motor ability scores in terms gender effect when partial out the age effect, results showed that there was no gender difference in motor ability scores. If age effect has not been adjusted, significant gender differences existed in the children's motor performance scores. This study result has shown that age is a confounding variable which is in agreement with Wong (2004) results stating that elder children performed better than younger counterparts in locomotor, object control, and total scores of TGMD-2.
This study did not find any relationship between children's body mass index and their motor performance when adjusted by age effect. This result was different from the study by D'Hondt, Deforche, De Bourdeaudhuij, and Lenoir (2009). They assessed the Movement Assessment Battery for children aged 5-10 years and found that scores for balance and ball skills were better in normal-weight and overweight children as compared with their obese counterparts.

Another purpose of the present study was to determine the influence of the types of preschools (large play area vs. small play area) on the preschoolers' motor performance. The present study found significant difference between two preschool types. For locomotor skills, children of preschools with larger play area performed better than those from preschools with smaller play area. However, a reverse pattern emerged for object control skills, in which children of preschools with larger play area out- 
performed those from preschools with smaller play area. In a review paper on environmental factors affecting preschoolers' motor development, schooling of private vs. public was found to be an influencing factor on children's motor skills (Venetsanou \& Kambas, 2010). A possible explanation for better locomotor skills in children from preschools with larger play area may be due to more opportunities in practicing locomotor skills such as running and leaping which requires a spacious area for locomotor activities. In contrast, development of object control skills does not need large spacious play area, this may be an explanation that children from preschools of small play area have better performance scores in object control than those from preschools of large play area. However, further studies are needed to look at the effect of other environmental variables such as school physical space, school curriculum as well as children's home space and physical activity participation patterns in order to help explaining the contradicting results of the differences in play area size of preschools and the children's motor ability.

Apart from the influence of the type of preschools, this study found that Hong Kong preschool children seemed to do better in object control skills. When computing mean percentiles based on norms provided by Ulrich (2000), the mean locomotor percentile and the mean object control percentile were $45.3 \pm 26.0$ and 49.6 \pm 28.4 , respectively. These results mean that Hong Kong children's motor performances fall in the median range in object control skills, but their motor performances fall below the median range in locomotor skills. A contradictory finding was shown by Pang and Fong (2009). When they assessed Hong Kong children ages 6-9, the results showed that children performed better in locomotor skills than object control skills. An implication of this study on preschool children may suggest that teachers of early childhood need to focus on the children's locomotor skill development when they design for activity curriculum. On the other hand, as there are gender differences in locomotor and object control skills, teachers do not need to accommodate for this in teaching gross motor activities.
There were few limitations in this study. First, a larger sample size would be more representative. Second, curriculum contents should be compared between the two types of preschools with either larger or smaller play area. Third, additional information about the socioeconomic status of the children from the two types of preschools should be obtained.

\section{Acknowledgement}

Thanks are extended to Ms. Eunice Kuk and Mr. Yuen Chi Kin for assisting data collection of this study.

\section{References}

Clark, J. E., \& Metcalfe, J. S. (2002), The mountain of motor development;: A metaphor. In J. E. Clark \& J. H. Humphrey (Eds.), Motor development: Research and review (Vol. 2, pp. 163-190). Reston, VA: National Association of Sport and Physical Education.

Choi Tse, K. (2004). A preliminary study on gross motor performance of Hong Kong children aged 6-8 years. Journal of Physical Education \& Recreation (Hong Kong), 10(2), 67-72.

D’Hondt, E., Deforche, B., De Bourdeaudhuij, I., \& Lenoir, M. (2009). Relationship between motor skill and body mass index in 5- to 10-year-old children. Adatped Physical Activity Quarterly, 26, 21-37.

Eaton, W., \& Enns, L. (1986). Sex differences in human motor activity level. Psychological Bulletin, 100, 1928.

Elisana, P., Konstantina, K., \& Vasilios, G. (2005). Gender differences in musical aptitude, rhythmic ability and motor performance in preschool children. Early Child Development and Care, 175(4), 361-369.

Gallahue, D. L., \& Ozmun, L. C. (2006). Understanding motor development: infant, children, adolescents, adults. Dubuque, IA, W.C. Brown and Benchmark.

Giagazoglou, P., Karagianni, O., Sidiropoulou, M., \& Salonikidis, K. (2008). Efects of the characteristics of two different preschool-type setting on children's gross motor development. European Psychomotricity Journal, 1(2), 54-60. 
Haga, M., Pedersen, A. V., \& Sigmundsson, H. (2008). Interrelationship among selected measures of motor skills. Child Care Health Development, 34(2), 245-8.

Haywood, K. M., \& Getchell, N. (2009). Lifespan motor development $\left(5^{\text {th }}\right.$ ed.). Champaign, IL: Human Kinetics.

Livonen, S., Saakslahti, A., \& Nissinene, K. (2011). The development of fundamental motor skills of four- to five-year-old preschool children and the effects of a preschool physical education. Early Child Development \& Care, 181(3), 335-343.

Pang, A., \& Fong, D. T. (2009). Fundamental motor skill proficiency of Hong Kong children aged 6-9 years. Research in Sports Medicine, 17(3), 125-134.

Payne, V. G., \& Isaacs, L. D. (2008). Human motor development: A lifespan approach. $\left(7^{\text {th }}\right.$ ed.). Boston, IL: McGraw-Hill.

Pennington, \& Kelly, R. (2002). Gender differences in gross and fine motor abilities in preschoolaged children in West Virginia. M. A. dissertation, Marshall University, United States - West Virginia. Retrieved January 10, 2008, from ProQuest Digital Dissertations database. (Publication No. AAT 1415587).

Roth, K., Ruf, K., Obinger, M., Mauer, S., Ahnert, J., Schneider, W., Graf, C., \& Hebestreit, H. (2010). Is there a secular decline in motor skills in preschool children? Scandinavian Journal of Medicine \& Science in Sports, 20(4), 670-678.
Shala, M. (2009). Assessing gross motor skills of Kosovar preschool children. Early Child Development and Care, 179(7), 969-976.

Ulrich, D. A. (2000). Test of Gross Motor Development-2. Austin, TX: Pro-Ed.

Venetsanou, F., \& Kambas, A. (2010). Environmental factors affecting preschoolers' motor development. Early Childhood Educational Journal, 37, 319-327.

Wang, J. H. (2004). A study on gross motor skills of preschool children. Journal of Research in Childhood Education, 19(1), 32-43.

Wong, K. Y. A. (2006). Construct validity of the test of gross motor development. Unpublished doctoral dissertation, Hong Kong Baptist University, Hong Kong.

\section{Correspondence:}

Prof Bik CHOW,

Department of Physical Education,

Hong Kong Baptist University,

Kowloon Tong, HONG KONG.

Email: bchow@hkbu.edu.hk 